\author{
J. Trip \\ C.G. Faber \\ H.B. Ginjaar \\ B.G.M. van Engelen \\ G. Drost
}

\section{Warm-up phenomenon in myotonia associated with the V445M sodium channel mutation}

Received: 14 May 2006

Received in revised form: 25 June 2006

Accepted: 11 July 2006

Published online: 2 March 2007

Sirs: Myotonia is a clinical phenomenon consisting of uncontrolled temporary muscle stiffness after voluntary or evoked muscle contractions [1]. It is a cardinal symptom in non-dystrophic myotonias, including chloride and sodium channelopathies. Myotonia typically occurs after a period of rest and decreases with continuing exercise, commonly referred to as the warm-up phenomenon. This is in contrast with what occurs in paradoxical myotonia, where muscle stiffness increases as a result of continuing exercise.

J. Trip, MD $(\bowtie) \cdot$ C.G. Faber, MD, PhD Dept. of Neurology

University Hospital Maastricht

PO Box 5800, 6202 AZ,

Maastricht, The Netherlands

Tel.: +31-43-3877058

Fax: +31-43-3877055

E-Mail: J.Trip@neurologie.azm.nl

H.B. Ginjaar, molecular geneticist, $\mathrm{PhD}$ Dept. of Human and Clinical Genetics University Medical Centre Leiden

Leiden, The Netherlands

B.G.M. van Engelen, MD, $\mathrm{PhD}$

G. Drost, MD

Neuromuscular Centre Nijmegen

Institute of Neurology

Radboud University Nijmegen Medical

Centre, The Netherlands
The warm-up phenomenon is an established clinical feature in chloride channelopathies, both in recessive myotonia congenita (Becker's disease) as well as in dominant myotonia congenita (Thomsen's disease). It has also been shown to occur in limb muscles of patients with a sodium channelopathy $[1,4]$. By contrast, paradoxical myotonia has been established by others as the characteristic feature of sodium channel myotonias [3].

Thus, unlike the phenotypic homogeneity of chloride channelopathies, sodium channel mutations are associated with a broad spectrum of clinical phenotypes [5]. Here we report three patients with a predominant and generalised warm-up phenomenon associated with the V445M missense mutation of the SCN4A gene encoding the alpha-subunit of the voltage gated sodium channel.

Three patients, from two families, with an autosomal dominant non-dystrophic myotonia and a predominant warm-up phenomenon were referred to our clinic. All patients had complaints of generalised muscle stiffness since birth and had earlier been diagnosed as Thomsen's disease, but recent chloride channel gene (CLCN1) mutation screening was negative. Clinical myotonia was generalised, severe and painful. All patients noticed aggravation of myotonia at cold temperatures and only one patient reported aggravation after eating potassium rich food. They all used sodium channel blockers (mexiletine $200 \mathrm{mg}$ three times a day, procainamide $1000 \mathrm{mg}$ three times a day and quinine $200 \mathrm{mg}$ three times a day respectively) with a good subjective effect. Needle EMG of all patients revealed myotonic discharges in all muscles investigated (left biceps muscle, right first interosseus muscle, right rectus femoris muscle, left tibialis anterior muscle and left orbicularis oculi muscle). We measured the warm-up phenomenon in three different muscle groups during a drug free period. The warm-up phenomenon of eyelid muscles and right hand flexor muscles was quantified by measuring the difference between two relaxation times timed with a stopwatch - , i.e. after maximum voluntary contraction of three seconds following ten minutes of rest and after ten successive contractions. For leg muscles we compared the first and tenth trial on a 'chair test' in which the time required to rise from a standardised chair, to move around it and to sit down again was measured. DNA extracted from $20 \mathrm{ml}$ of blood was screened for mutations in SCN4A by direct nucleotide sequence analysis.

All patients showed a marked generalised warm-up phenome-

Table 1 Clinical relaxation times (in seconds) of three patients after the first $\left(1^{\text {st }}\right)$ and tenth $\left(10^{\text {th }}\right)$ maximum voluntary contraction of eyelid muscles (eyes), right hand flexor muscles (hand) and leg muscles (legs)

\begin{tabular}{lccc}
\hline Age (years)/Sex & $\begin{array}{c}\text { Patient A } \\
29 / \mathrm{M}\end{array}$ & $\begin{array}{l}\text { Patient B } \\
52 / \mathrm{F}\end{array}$ & $\begin{array}{c}\text { Patient C } \\
68 / \mathrm{M}\end{array}$ \\
\hline Eyes $\left(1^{\text {st }}\right)$ & 3.77 & 25.00 & 17.46 \\
Eyes $\left(10^{\text {th }}\right)$ & 1.37 & 6.57 & 1.35 \\
Hand $\left(1^{\text {st }}\right)$ & 7.97 & 13.93 & $<1.00^{*}$ \\
Hand $\left(10^{\text {th }}\right)$ & $<1.00 *$ & 1.11 & $<1.00^{*}$ \\
Legs $\left(1^{\text {st }}\right)$ & 15.47 & 6.45 & 9.70 \\
Legs $\left(10^{\text {th }}\right)$ & 6.16 & 5.09 & 5.67 \\
* No detection of clinical myotonia & & &
\end{tabular}


non (Table 1). Direct nucleotide sequence analysis of all three patients showed the same missense mutation (c.1333G >A; p.V445M) in $S C N 4 A$.

The V445M sodium channel mutation was first reported by Rosenfeld et al. causing a painful myotonia congenita [4]. The warm-up phenomenon was mentioned in one patient. Here we report three patients with a predominant and generalised (eyelid muscles, right hand flexor muscles and leg muscles) warm-up phenomenon in association with the same V445M sodium channel mutation. Although quantitative computer analysis for the warmup phenomenon of a single muscle group has already been developed, we used clinical tests in order to be able to measure this phenome- non in three various muscle groups [2].

For a definite molecular diagnosis clinicians should be aware that a predominant and generalised warm-up phenomenon may be found in chloride channelopathies but also in sodium channelopathies. A definite diagnosis is important for informing patients about their disease, orienting therapy and genetic counselling [5]. Thus, in patients with severe, painful myotonia in combination with a clear warm-up phenomenon, we recommend screening of SCN4A with particular attention for the V445M mutation.

Funding/Support This study was financially supported by a research grant of the 'Prinses Beatrix Fonds' (MAR04-0118).

\section{References}

1. Lehmann-Horn F, Rüdel R, Jurkat-Rott K (2004) Nondystrophic myotonias and periodic sparalysis. In: Engel AG, Franzini-Armstrong C (eds) Myology, $3^{\text {rd }}$ edn. Mc Graw-Hill, New York, pp 12571300

2. Logigian EL, Blood CL, Dilek N, Martens WB, Moxley RT $4^{\text {th }}$, Wiegner AW, Thornton CA, Moxley RT $3^{\text {rd }}(2005)$ Quantitative analysis of the "warm-up" phenomenon in myotonic dystrophy type 1. Muscle Nerve 32:35-42

3. Ptacek LJ, Johnson KJ, Griggs RC (1993) Genetics and physiology of the myotonic muscle. N Engl J Med 328:482-9

4. Rosenfeld J, Sloan-Brown K, George AL Jr (1997) A novel muscle sodium channel mutation causes painful congenital myotonia. Ann Neurol 42:811-814

5. Vicart S, Sternberg D, Fontaine B, Meola G (2005) Human skeletal muscle sodium channelopathies. Neurol Sci 26:194-202 